\title{
CONSIDERAÇÕES SOBRE RITO E TEATRO EM ARTAUD
}

\author{
Ismael Scheffler ${ }^{1}$
}

\begin{abstract}
Resumo
Este artigo aborda questões sobre a relação que Artaud estabelece entre teatro e rito. Para melhor compreender o rito, tomo conceitos de Mircea Eliade que propiciam uma compreensão abrangente do termo e uma leitura sobre as propostas artaudianas. A partir disto, $\mathrm{o}$ artigo pontua sobre o desempenho dos diferentes papéis (diretor, ator e espectador) nas propostas de Artaud e tece algumas considerações sobre Os Cenci, realização teatral que deveria ter sido a concretização de suas concepções.
\end{abstract}

Palavras-chaves: Artaud, rito, teatro sagrado.

\begin{abstract}
This article approaches issues regarding the relationship Artaud established between theatre and rite. In order to better grasp the meaning of rite, concepts were taken from Mircea Eliade's work to promote a comprehensive understanding of this term and to obtain a reading on Artaudian propositions on the subject. Whereof, the article addresses the performance of different roles (director, actor and spectator) in Artaud's proposals and comments on Les Cenci, the theatrical act that should have been the realization of Artaud's conceptions.
\end{abstract}

theatre.

Keyworks: Artaud, rite, holy

\section{Conceito de rito}

Ao escrever sobre o Teatro de Bali, Artaud faz várias referências aos gestos rituais e aspectos ritualísticos deste. $\mathrm{O}$ autor destaca certa mecanização gestual dos atores-bailarinos, a precisão fixada, bem como o desempenho com uma solenidade. Apesar dessas indicações sobre os gestos e a atitude dos atores, não é meramente o cumprimento de ações rígidas pré-existentes que caracteriza o rito. A realização daquelas ações corresponderia à utilização de gestos, sons e objetos de forma pouco significativa. Felipe Reyes Palacios adverte que muitos trabalhos contemporâneos inspirados em Artaud incorrem no erro de se apropriar de imagens "sagradas", em uma "idolatria das formas", questão também destacada por Peter Brook em $O$ teatro e seu espaço. Muitos

\footnotetext{
${ }^{1}$ Ismael Scheffler é aluno de doutorado do Programa de Pósgraduação em Teatro da UDESC. Mestre em

Teatro e professor na Universidade Tecnológica Federal do Paraná - Curitiba. É ator e diretor teatral.
} 


\section{Urdimento}

${ }^{2}$ Christopher Innes salienta que existem relações com a Bauhaus, onde se realizavam experiências tomando 0 teatro como arte espacial, determinado por seqüências rítmicas criteriosamente marcadas (Ballet Triádico). 0 questionamento da centralidade do texto também não era exclusividade de Artaud. Roubine aponta Craig, Meyerhold e Gastón Baty, além de Artaud, como precursores nesse ponto. artistas do teatro ocidental, interessados em um teatro sagrado, acabam preocupando-se com a forma ou o aspecto ritual; acreditam que se tomarem formas cerimoniais de alguma tradição religiosa ou esotérica consideradas sagradas, estarão pondo o público em comunhão com o metafísico, só por serem meios rituais "de eficácia comprovada" em sociedades arcaicas ou tradicionais, como se somente a forma dos elementos cênicos fosse suficiente para isso (PALACIOS, 1991, p. 24).

Artaud considerava fundamental uma renovação formal, distanciandose do naturalismo em voga. Quando escreve sobre a restituição dos aspectos religiosos e metafísicos, não se refere a uma mera apropriação. De fato, por não ter realizado suas propostas e por não ter elaborado sistematicamente suas idéias, Artaud parece abrir margem a essa distorção, idéia também partilhada por Cassiano Syndow Quilici que apropriadamente relembra que "a ausência de método e a linguagem cifrada dos escritos artaudianos teriam aberto espaço para esse tipo de apropriação" (2004, p. 137).

Artaud, porém, afirma que "há toda uma profusão de gestos rituais cuja chave não temos e que parecem obedecer a determinações musicais extremamente precisas, com alguma coisa a mais que não pertence em geral à música e que parece destinada a envolver o pensamento, a persegui-lo, a conduzilo através de uma malha inextrincável e certa" [grifo meu] (ARTAUD, 1993, p. 53). Estes gestos, como o rito, possuem algo de envolvente, não perceptível de imediato. Como atesta o pesquisador argentino Raul Fernando Nader (199?, p. 278), "as ações rituais estão destinadas em primeiro lugar a preparar o homem para poder ascender ao sagrado”.

Conforme o cientista das religiões Mircea Eliade, o sagrado é uma das modalidades de se ser no mundo. O sagrado irrompe no mundo profano, regenerando-o, fazendo com que, através de uma epifania, o universo e o homem sejam renascidos. O sagrado revela uma instância superior além da transitoriedade da vida, atribuindo a esta um valor diferenciado.

Artaud prevê uma série de recursos e efeitos cênicos para o teatro a fim de envolver, ampliar as experiências e impactar o público. Alguns destes meios são apresentados de forma inovadora, outras propostas também apareceram em outros encenadores e pesquisas ${ }^{2}$. No entanto, é importante destacar que a multiplicidade de formas de expressão que Artaud propõe para seu teatro não possui um fim em si mesmo, antes ele pretende conduzir o espectador para algo além, para outras dimensões da experiência ampliando as relações com o real. Ele vislumbra novas possibilidades para a encenação através da utilização de ecos, reflexos, manequins, "escorregaduras”, "cortes” (ARTAUD, 1995 , p. 54), 


\section{Urdimento}

gritos, lamentações, aparições, surpresas, golpes teatrais de todo tipo, beleza mágica das roupas feitas segundo certos modelos rituais, deslumbramento da luz, beleza encantatória das vozes, encanto da harmonia, raras notas musicais, cor dos objetos, ritmo físico dos movimentos cujo crescendo e decrescendo acompanhará a pulsação de movimentos familiares a todos, aparições concretas de objetos novos e surpreendentes, máscaras, bonecos de vários metros, mudanças bruscas da luz, ação física da luz que desperta o calor e ofrio, etc. (ARTAUD, 1993, p. 89)

Esses recursos, além de dinamizarem, enriquecem o leque de imagens passíveis de serem utilizadas, podendo conduzir a diferentes vivências e sensações, a experiências distintas do cotidiano, do teatro e da linguagem logocêntrica, sendo potencialmente evocadores. Para Quilici (2004, p. 32), Artaud propõe "[ $[.$.$] uma linguagem que, mais do que representar, pretende$ ser um modo de agir e afetar”.

Para a Hermenêutica Simbólica ${ }^{3}$, o rito é uma das maneiras do homem participar do sagrado. O rito não é apenas uma forma ou uma sucessão de ações repetitivas por hábito ou por pertencerem a determinada situação, como ações exteriores. $\mathrm{O}$ encontro do homem com o sagrado é o motivo central do rito, no qual ambos deixam de ser realidades separadas e se fundem em uma unidade (NADER, 199?, p. 282), uma vez que a manifestação do sagrado ocorre somente pela vivência pessoal, pela experiência.

Artaud, no Manifesto por um Teatro Abortado, esboça esta idéia de operação no espírito, transformando não apenas palavras, ações ou objetos, mas alterando o âmago da vida:

Não é ao espírito ou aos sentidos dos espectadores que nos dirigimos, mas a toda sua existência, a deles e a nossa. (...) Uma parcela de nossa vida profunda está engajada aí dentro (...). O espectador que vem ver-nos sabe que vem oferecer-se a uma operação verdadeira, onde não somente seu espírito, mas também seus sentidos e sua carne estão em jogo. Ele irá doravante ao teatro como vai ao cirurgião e ao dentista. No mesmo estado de espírito, pensando, evidentemente, que não morrerá, mas que é grave e que não sairá de dentro inato (ARTAUD, 1995, p. 31).

O rito é um espaço de ação, de realizá-la e de sofrê-la, lugar de acontecimento, lugar de epifania. O rito distingue-se de manifesto teológico, pois neste âmbito trabalharia para a elaboração de um produto, a apresentação de uma idéia, um conceito, um conjunto de dogmas, um espetáculo, e deixaria
${ }^{3}$ Os conceitos de rito, mito e sagrado em que este texto está baseado, são tomados da Hermenêutica Simbólica, campo da antropologia filosófica, que encontra em Mircea Eliade um de seus expoentes. Nader realiza uma leitura da obra de Eliade, sistematizando conceitos. Sobre a Hermenêutica Simbólica, ver: SCHEFFLER, Ismael. A hermenêutica simbólica como possibilidade epistemológica para o estudo do espaço teatral. Revista on-line Periscope Magazine. 


\section{Urdimento}

${ }^{5} 2004$ e 2005 na sede do Grupo Galpão em Belo Horizonte; 2006 na sede Barracão Teatro em São Paulo; e em 2007 será realizado em Porto Alegre na sede do Grupo de Atuadores Terreira da Tribo Ói Nóis Aqui Traveiz.

de ser um espaço aberto de produção, podendo ser simplesmente consumido pelo espectador. Seria o que Urias Corrêa Arantes (1998, p. 194) chama de "palco teológico", dominado pela palavra que governaria a cena de fora. O rito não é um produto apreciável, observável - é um encontro, "a chave de acesso ao mundo sobrenatural e verdadeiro” (NADER, 199?, p. 277). Ele restabelece as forças e reconstrói o mundo através da celebração mítica.

Artaud trabalha com a palavra repetição aplicando-a em dois sentidos completamente diferentes. O primeiro, uma repetição da forma vazia, automática, sem vida. Na citação a seguir ele emprega o termo "rito" no sentido de simples repetição de ações, desprovido de um sentido maior: "um espetáculo que se repete todas as noites segundo os mesmo ritos, sempre idênticos a si próprios, não pode conquistar nossa adesão. Temos necessidade de que o espetáculo ao qual assistimos seja único, que ele nos dê a impressão de ser imprevisto e tão incapaz de se repetir quanto qualquer ato da vida, qualquer acontecimento trazido pelas circunstâncias” (ARTAUD, 1995, p. 33-4).

Em contrapartida, ele deslumbra-se com os gestos do Teatro de Bali e aspira que seu Teatro da Crueldade seja marcado do começo ao fim, o que impediria movimentos perdidos (ARTAUD, 1993, p. 95), ocorrendo a repetição precisa. Isso é reforçado quando menciona que os espetáculos "serão rigorosamente elaborados e pré-estabelecidos definitivamente antes de serem encenados" (ARTAUD, 1995, p. 83). A repetição está relacionada diretamente ao tempo, que, nestes dois casos, é também distinto: a repetição estéril se situa dentro de um tempo que nada envolve, qualitativamente igual, um tempo profano; a repetição com sentido, está no âmbito do sagrado, pois, como diz Nader (199?, p. 282), "quando a ação [ritual] termina, o homem sai renovado e integrado a um cosmos pleno de sentido e significação”. A pessoa pelo rito tem acesso a essa supra-realidade que transfigura a si e ao seu esquema de vida.

O rito atualiza um evento sagrado dos primórdios que está colocado na forma de um mito. A vivência deste mito através do rito provoca uma saída da duração temporal ordinária, uma parada periódica na duração temporal profana, criando um tempo sagrado que não se esgota. Esse tempo é "circular, reversível e recuperável, espécie de eterno presente mítico que o homem reintegra periodicamente pela linguagem dos ritos" (ELIADE, 2001, p. 64). No rito, tudo é regenerado, criado de novo, renovado no que se gastou. E nisso o homem se identifica com o ato cosmogônico, de destruição e recriação do Mundo. O rito cosmogônico é terapêutico, pois a partir dele se começa outra vez a existência. "É graças a este eterno retorno às fontes do sagrado e do real que a existência humana parece salvar-se do nada e da morte” (ELIADE, 2001 , p. 94). A vida não pode ser reparada, mas somente recriada pela repetição 


\section{Urdimento}

simbólica da cosmogonia. Encontrar um tempo sagrado não é desejar apenas o contato com os deuses, mas é recuperar o mundo puro, que atende a uma nostalgia do Ser. Mircea Eliade (2001, p. 59) declara que "é preciso retornar à 'página branca' da existência, ao começo absoluto, quando nada se encontrava ainda maculado, quando nada estava ainda estragado”. É nesse sentido que a repetição para Artaud tem razão de ser, na medida em que propicia ao homem reatar com a Vida e não se separar dela. $\mathrm{O}$ ato teatral como ato ritual não o é pela aparência, mas pela finalidade.

Não se trata de levar ao palco temáticas religiosas, que seriam representadas de forma mais ou menos convencional. O teatro sagrado não é aquele que necessariamente trabalha com "temas religiosos". Mais do que falar sobre, o que se pretende é proporcionar uma experiência do sagrado. $O$ rito, portanto, não deve ser compreendido como expressão formal de um conteúdo religioso. Ele deve possuir um poder operatório, desencadeando uma vivência de natureza singular, "mítica", mas num sentido arcaico e primitivo (QUILICI, 2004, p. 38).

\section{Um ato coletivo}

Um fator característico dos ritos é o seu sentido de coletividade. Conforme Nader (199?, p. 280), mesmo que um rito seja individual, ele está respaldado pela aprovação de um grupo social e todo grupo se expressa através dele. Palacios (1991, p. 90) destaca que "os ritos surgem no seio dos grupos reunidos e derivam sua legalidade das necessidades sociais que satisfazem, por isso a forma que assumem é eminentemente coletiva" ${ }^{4}$. Na medida em que Artaud pretende um teatro ritual, poderíamos perguntar quem é o coletivo que o cria e mantém sua existência. Haveria como identificar uma unidade social que partilhasse das mesmas necessidades espirituais com fins a reviver experiências de renovação comuns? Se considerarmos que as sociedades ocidentais são multifacetadas, poderíamos supor, então, que um teatro sagrado implicaria numa formação ou afirmação de "redutos" ou segmentos. No entanto, a arte em geral, embora proclamada a destinar-se a todos, não acaba por fim restringindo-se a "redutos", que percebem que, de alguma forma, a arte, aquela arte, lhe é necessária?

No Teatro da Crueldade, Artaud (1993, p. 96) falando sobre o público diz que primeiro é preciso que haja esse teatro. Com essa declaração ele parece esgueirar-se da questão, ou crer que, ao ser realizado, o público se reuniria segundo a identificação, como se a existência de seu teatro fizesse com que as pessoas percebessem sua própria necessidade latente. Christopher INNES (1992, p. 110) elabora críticas contundentes afirmando que Artaud "trabalhou

${ }^{4}$ Quilici tece um interessante estudo retomando a trajetória antropológica do "ritual", passando por Durkheim, que desenvolve uma explicação sociológica do rito, por Van Gennepp, que trabalha em torno do tema "ritos de passagem", e por Victor Turner em suas relações entre o teatro e o ritual. Em seu livro aborda de forma atenta à questão do rito como expressão coletiva. 


\section{Urdimento}

${ }^{5}$ DORT, B. A vanguarda em suspenso. Théâtre populaire. n. 18, 1.5.1956; texto reproduzido (e ligeiramente modificado) em Théâtre public, Seuil, 1967, p. 245 (VIRMAUX, 2000, p. 200).
${ }^{61}$ Seria mesmo estranho para alguém que dizia querer "fugir da civilização européia", manter-se no âmbito da universidade e do jornalismo" (QUILICI, 2004, p. 172). em busca de efeitos psicossociais sem considerar exatamente a quem afetariam. Para que seu estilo fosse apropriado a suas metas, Artaud teria que considerar as pautas de conduta estabelecidas dos espectadores, já que só assim poderia predizer acertadamente as respostas e selecionar seqüências de imagens para obter reações precisas”. Essa questão, no entanto, não é tema desenvolvido significativamente nos escritos de Artaud.

Outro aspecto relacionado ao público é abordado por Jorge Dubatti (2002, p. 35), quando ele lembra que na proposta de Artaud, o público "perde a distância de observador do acontecimento teatral e se fusiona de tal maneira que deixa de ser espectador para se transformar em participante-oficiante" da cerimônia mágica. Dessa maneira, não existiria mais uma simples recepção estética de um objeto artístico por parte do espectador. Artaud, contudo, não define o que seria essa participação que parece implicar em ação. Para Bernard Dort, este seria o grande defeito do O teatro e seu duplo: "sonhar com um teatro sem pensar num público; preconizar um grande teatro de participação sem se interrogar sobre a natureza e o papel dessa participação" (DORT ${ }^{5}$ apud VIRMAUX, 2000, p. 200). Vale lembrar, no entanto, que nos ritos xamânicos, nem todos que o assistem necessariamente fazem parte da ação - alguém faz por eles e eles compactuam com o que está sendo feito. Participam porque atestam e partilham, aprovam e fazem parte.

Os ritos não operam com a divisão palco-platéia, mas com diferentes níveis de participação num acontecimento. Se há aqueles que conduzem o desencadeamento das ações, em função de um saber que os diferencia, os demais não estarão ali apenas para ver, ouvir ou "ler" o que lhes será apresentado. Deverá haver uma predisposição outra de "coparticipação", uma mobilização corporal mais intensa, uma predisposição ao risco (QUILICI, 2004, p. 194).

Artaud acreditava no teatro como atividade social, coletiva, com potencial de transformação da cultura. Por outro lado, ele parece idealizar um rito que permanece unicamente dentro de si, composto por múltiplas fontes de diversas culturas, sem interação com pesquisas teóricas ${ }^{6}$ (mas sendo teorizador), elaborado principalmente por sua intuição, como reflexo de uma ânsia pessoal, de uma necessidade interna. As referências que Artaud manipulou corresponderiam, assim, a subsídios que o inspiraram em sua elucubração.

Também com relação ao desempenho do diretor e dos atores, Artaud não aprofundou muito, esboçando idéias sem delinear com precisão metodologias de trabalho. Ele propõe a unificação da figura do diretor e do autor como o criador absoluto desse universo, "uma espécie de ordenador mágico, um mestre de cerimônias sagradas” (ARTAUD, 1993, p. 56). E 


\section{Urdimento}

define o ator tomando-o "ao mesmo tempo [como] um elemento de primeira importância, pois é da eficácia de sua interpretação que depende o sucesso do espetáculo, e [como] uma espécie de elemento passivo e neutro, pois toda iniciativa pessoal lhe é rigorosamente recusada” (ARTAUD, 1993, p. 95). Essa descrição se aproxima da definição de xamã que, sendo o centro do rito, age segundo um poder superior recebido que se apossa e manifesta através do homem, levando-o à nulidade do seu eu para dar lugar à força sobrenatural, uma possessão, um transe.

Essa idéia de transe poderia ser compreendida como um delírio anárquico, desregrado, uma histeria descontrolada; porém Alain Virmaux lembra que os transes sempre ocorrem dentro de um momento previsto nas liturgias dos ritos $^{7}$, e que Artaud pretende o transe através de métodos calculados, e não enlouquecidos. Podemos concordar com Virmaux (2000, p. 49) no sentido de que, para Artaud, "trata-se na verdade de mudar de pele, de se deixar habitar pelas forças mágicas”, tanto para os atores quanto para os espectadores. Entrar em contato com o sagrado pelo transe provoca uma fusão entre o homem e a força sagrada, transformando essas duas realidades distintas em uma unidade que é extremamente significativa, visto que o sagrado se revela e se deixa conhecer, atribuindo ao homem que o experimenta um novo valor, sendo partícipe da santidade. A perda do próprio corpo e a possessão dele novamente implica num processo de "cosmização", de destruição e recriação do Mundo-corpo, pois, como destaca Eliade (2001, p. 141-4), existe uma correspondência entre o corpo e o Cosmos. Entregar-se ao divino e deixarse habitar por ele é experimentar a passagem de um corpo condicionado a um corpo não condicionado, totalmente livre, aberto, entregue, renascido. A idéia do corpo sem órgãos perpassa pelo desejo de um ser humano liberto dos condicionamentos e automatismos físicos e mentais ${ }^{8}$.

\section{Os Cenci}

$\mathrm{O}$ que poderíamos tomar como modelo teatral mais próximo à concretização das propostas de $\operatorname{Artaud}^{9}$ seria seu espetáculo Os Cenci, apresentado em 1935, poucos meses depois de publicados seus manifestos do Teatro da Crueldade (o que gerou grande expectativa na época).

Artaud trabalhou com uma adaptação da história da família italiana Cenci, baseado nos textos de Stendhal e Percy Shelley. O encenador via na história aspectos potenciais míticos (do pai destruidor).

De maneira geral, a história de Les Cenci gira em torno da personagem do conde Francisco Cenci. As fontes históricas trabalhadas por Stendhal nos falam de um homem muito rico nascido em 1526,
${ }^{7}$ Virmaux (2000, p. 46-49), em Artaud e o teatro, desenvolve uma abordagem sobre o transe que, embora curta, é bastante esclarecedora.

${ }^{8}$ Ver o texto 0 homem-árvore - carta a Pierre Loeb (ARTAUD, 1988, p. 105-110) e Para acabar com o julgamento de Deus (WILLER, 1986, p. 161-2).

${ }^{9}$ Innes lança um olhar para os espetáculos realizados por Artaud no período do Teatro Alfred Jarry (1926 a 1929), e destaca nessas produções aspectos presentes nas propostas subseqüentes de Artaud. Este pesquisador enfatiza a pouca exploração desses espetáculos como forma de compreender Artaud. No entanto, é necessário também reconhecer que o próprio Artaud não os utiliza significantemente como referência para seus posteriores escritos sobre o Teatro da Crueldade. 
filho do tesoureiro do Papa Pio V. Tornou-se célebre por sua violência e pelos inúmeros casos extraconjugais que lhe valeram diversos processos, dos quais se livrava através de subornos. Afirmava o ateísmo numa época caracterizada pela perseguição às heresias e pelo trabalho da Inquisição. Tinha sete filhos, entre os quais a jovem Beatriz, célebre por sua beleza, retratada em diversos quadros da época. [...] Beatriz tinha então dezesseis anos. [...] Na primeira cena da peça de Artaud, Francisco Cenci recusa-se a se arrepender de suas faltas diante de um representante do Papa (Camilo). Promete, ao invés disso, uma sucessão de crimes, atingindo sua própria família, reservando os requintes de crueldade para sua filha. Na cena 3 do primeiro ato, promove um banquete orgiástico com membros da Igreja e do Estado, bebendo simbolicamente o sangue dos próprios filhos. Na seqüencia da trama, violenta Beatriz, que não confia mais na possibilidade de seu pai ser julgado e condenado pelas instituições. A filha resolve então fazer justiça por conta própria: contrata dois criados para assassinar o pai. O crime é descoberto e Beatriz acaba sendo presa pela Igreja e obrigada a assinar sua confissão. Na versão de Artaud, ao invés da guilhotina, Beatriz é condenada a morrer torturada numa roda, instrumento típico da Inquisição (QUILICI, 2004, p. 148-9).

O espetáculo, que escreveu, dirigiu e atuou, marca a despedida de Artaud dos palcos. O espetáculo ficou muito aquém do ideal artaudiano, recebendo inúmeras críticas, o que faz com que os estudiosos de Artaud se empenhem por tentar compreender os motivos de tal frustração.

Para Palacios (1991, p. 97), a encenação de Os Cenci “não obteve os frutos apetecidos, entre outras razões, por não ter conseguido estabelecer uma forma precisa de relação entre diretor e ator, uma técnica, um método susceptível de progresso, verificação e retificação”.

Martin Esslin (1978, p. 40), destaca que, além de Artaud ter escolhido para Os Cenci um local que contradisse suas propostas (Teatro Folie-Wagran), ele se deparou com muitas dificuldades com os atores que não entendiam suas idéias, o que o deixava nervoso, e isso transmitia a eles. Innes, no capítulo dedicado a Artaud, concede especial atenção ao espetáculo Os Cenci, e destaca que, longe da idéia de um teatro anárquico, Artaud possuía para esta encenação uma preocupação com os detalhes e as marcações, pretendendo "uma mecanização organizada que Artaud comparou com o funcionamento das engrenagens de um relógio” (INNES, 1992, p. 80), com utilizações do espaço geometricamente, pautas vocais e uso de manequins, utilizando-se também de posturas exaltadas que lembram gestos típicos do cinema expressionista. 


\section{Urdimento}

Mesmo que Artaud tenha esboçado algumas questões, como uma técnica de respiração ${ }^{10}$ exposta em Um atletismo afetivo, e a necessidade de encontrar no corpo, à semelhança da medicina chinesa, pontos de apoio nos quais o ator possa "aumentar a densidade interior e o volume de seu sentimento" (ARTAUD, 1993, p. 135), ele não elabora uma técnica atoral para testar suas teorias, como Grotowski (1971, p. 69) também sublinha. Artaud não elabora nem fornece indicações sistemáticas, apenas alguns princípios gerais que, a despeito disso, não há como negar, estimulam a criatividade e o desejo pelo encontro de novas técnicas para o teatro ao longo do século XX.

Innes defende a idéia de que essa distância entre idealização artaudiana e sua prática se deve a uma tendência de "entusiasmos" que Artaud projetava além suas próprias opiniões:

Se os ensaios de Artaud eclipsaram suas realizações práticas é algo que se deve, tanto como qualquer outra coisa, a que prometem algo muito mais grandioso do que jamais poderia atingir na prática. Artaud tinha o hábito de exagerar em grau extremo. Ele mesmo tinha consciência disto como defeito, e em uma reveladora nota de uma carta, em que pedia a Jean Paulhan não publicar uma de suas críticas teatrais, pois o que havia escrito tinha muita pouca relação com o que tinha visto, fazia este comentário: "Não posso escrever sem entusiasmo e sempre vou muito longe." II Isto, mais que a falta de apoio econômico, é a razão da lacuna existente entre a teoria de Artaud e sua prática; e um bom exemplo desta lacuna é sua insistência no drama como "processo", como produto não terminado, no que comumente se considera "o teatro artaudiano" (INNES, 1992, p. 74-75).

\section{Algumas considerações}

Palacios ressalta que é importante para desvendar o que seria o rito no teatro artaudiano, identificar o mito a ser celebrado, pois todo rito é a celebração de um mito, e conseqüentemente os modelos que se pretende repetir no presente. "Em uma primeira tentativa de identificar o tipo de rito a que corresponderia a concepção teatral de Artaud, haveria que se levar em conta primeiramente esse conceito reitor" (PALACIOS, 1991, p. 65). Se de fato é verdade que o rito é o mito em ação ${ }^{12}$, a pergunta que teria que ser feita é: qual é o mito que Artaud quer reviver? O que deveria ser renovado, restaurado, instituído, celebrado pelo rito? Como já mencionado, pode-se perceber a reincidência da destruição e reconstrução para se encontrar uma existência significativa. A ação profunda para Artaud perpassa por uma cura do ser humano como um todo: cura do corpo, cura da alma, cura do espírito,
${ }^{10}$ Em Em Busca de um Teatro Pobre, Grotowski afirma que Artaud fez uma interpretação errônea dos textos orientais ao estabelecer sua proposta de respirações. Em seus textos 0 Teatro de Seraphin e Um Atletismo Afetivo, Artaud abordará questões sobre a atuação.

${ }^{11}$ ARTAUD. Oeuvres Complètes, v. 3.16 de outubro de 1934, p. 308.

${ }^{12}$ Para a Hermenêutica Simbólica, 0 mito é o relato da irrupção da ação do sagrado, é uma narrativa dramática ou histórica na qual imagens arquetípicas ou simbólicas se ligam umas às outras, formando um relato que possui características do sagrado. 0 mito, segundo Eliade, é uma história, um relato do verdadeiramente real que afeta a existência do homem e lhe atribui um sentido. 
cura social, cura cósmica, na qual homem e universo se reencontram - cura que ele ansiava desesperadamente para si - não se concentrando apenas em uma única dimensão "espiritual”. Então, poderemos concluir com Palacios (1991, p. 32) que "é esta parte da experiência ritual em que se concentra o interesse de Artaud: a crise que 'o retorno’ está destinado a provocar de maneira implacável”.

Interessante, porém, é a relação de Artaud com o teatro, pois como ressalta Teixeira Coelho (1982, p. 100), "Artaud não chegou a pedir o fim do espetáculo e o fim do espectador, não chegou a ir até a essência alquímica do teatro, ao teatro radical”. Ele continuou buscando, por um lado, o teatro, expressão artística, e por outro, buscando experiências e referências em culturas diversas, como entre os índios mexicanos Tarahumaras (poucos meses depois de Os Cenci, Artaud parte em viagem ao México). Segundo Quilici (2004, p. 21), "Artaud fez do teatro não só um campo de atuação e expressão cultural, mas uma forma de engajamento num processo radical de reconstrução de si mesmo.” Artaud se mantém e insiste em se manter relacionado ao teatro.

Arantes (1998, p. 196), porém, afirma que o que ele propõe não é mais espetáculo, mas uma transgressão dos "limites das interdições éticometafísicas”. Artaud dá características de espetáculo a sua vida, funde vida e arte e pretende um teatro que também o faça, deixando em aberto a viabilidade de sua realização. Permanece o questionamento se, levado de fato às vias finais, Artaud ainda estaria desenvolvendo "arte".

No Manifesto por um Teatro Abortado, Artaud escreve:

Rumo a este teatro ideal, nós avançamos nós mesmos como cegos. Nós sabemos parcialmente o que queremos fazer e como poderíamos realizá-lo materialmente, mas temos fé em um acaso, em um milagre que se produzirá para nos revelar tudo o que ignoramos ainda e que dará toda a sua vida superior profunda a esta pobre matéria que nós encarniçamos em amassar. Fora portanto da maior ou menor consecução de nossos espetáculos, os que vierem a nós compreenderão que participam de uma tentativa mística... (1995, p. 38-39).

A tentativa mística, ideal, permaneceu nas intenções de Artaud ao longo de sua vida e sobre elas ainda muitos permanecem inspirados. 


\section{Referências bibliográficas}

ARANTES, Urias Corrêa. Artaud: teatro e cultura. Campinas: UNICAMP, 1988.

ARTAUD, Antonin. Linguagem e Vida. Tradução e organização: J. Guinsburg; Sílvia Fernandes Telesi; Antonio Mercado Neto. São Paulo: Perspectiva, 1995.

O teatro e seu duplo. São Paulo: Martins Fontes, 1993.

BROOK, Peter. O teatro e seu espaço. Petrópolis: Vozes, 1970.

DUBATTI, Jorge. El teatro jeroglífico - herramientas de poética teatral. Buenos Aires: Atuel, 2002.

ELIADE, Mircea. O sagrado e o profano. São Paulo: Martins Fontes, 2001.

Mito e realidade. São Paulo: Martins Fontes, 1998.

ESSLIN, Martin. Artaud. São Paulo: Cultrix, 1978.

GROTOWSKI, Jerzy. Em busca de um teatro pobre. Rio de Janeiro: Civilização Brasileira, 1971.

INNES, Christopher. El teatro sagrado - el ritual y la vanguardia. México: FCE, 1992.

NADER, Raul Fernando. Mito, misterio y destino humano: (en el pensamiento de Mircea Eliade). Tucumán: Universidad Nacional de Tucumán, [199?].

PALACIOS, Felipe Reyes. Artaud y Grotowski: ¿̨el teatro dionisiaco de nuestro tiempo? México: Gaceta, 1991.

QUILICI, Cassiano Sydow. Antonin Artaud: teatro e ritual. São Paulo: Annablume; Fapesp, 2004.

SCHEFFLER, Ismael. A hermenêutica simbólica como possibilidade epistemológica para o estudo do espaço teatral. Revista on-line Periscope Magazine, Florianópolis, ano 2, n. 4, dez. 2002. Disponível em: <http://www.casthalia.com.br/ casthaliamagazine/ casthaliamagazine4.htm>

TEIXEIRA COELHO, José. Antonin Artaud: posição da carne. São Paulo: Brasiliense, 1982.

VIRMAUX, Alain. Artaud e o teatro. 2. ed. São Paulo: Perspectiva, 2000. 